\title{
EUCLIDES DA CUNHA HISTORIADOR: A REINVENÇÃO DO BANDEIRANTE EM OS SERTÕES
}

\author{
Danilo Zioni Ferretti \\ Doutor em História Social/USP. \\ Professor da Universidade Federal de São João Del Rei (UFSJ).
}

\section{Resumo}

Pretende-se abordar o aspecto histórico de Os sertões, privilegiando a relação de Euclides da Cunha com o processo de escrita de uma história paulista. Partindo da preocupação de Michel de Certeau com o lugar social de produção do texto histórico, analisa-se a inserção de Euclides da Cunha no grupo de historiadores da paulistanidade integrados no Instituto Histórico de São Paulo e a forma original como representou o bandeirante em Os sertões.

\section{Pallavras-chaves}

Os sertões $\bullet$ historiografia paulista $\bullet$ bandeirante.

\section{Abstract}

This article discusses the historical aspect of Os sertões highlighting the relationship of Euclides da Cunha with the writing of São Paulo state history. Using Michel de Certeau's preoccupation with the social place of production of a historical text, this article analyzes the inclusion of Euclides da Cunha in the group of paulistanidade historians associated with the Historical Institute of São Paulo and his representation of the bandeirante in Os sertões.

\section{Keywords}

Os sertões • São Paulo state history • bandeirante.

\footnotetext{
${ }^{1}$ Agradeço a Fábio Franzini a leitura e sugestões feitas e a Cameron Nimmo pela tradução do resumo.
} 


\section{Introdução}

Fruto de uma época de incipiente autonomia do campo intelectual, em que as áreas de saber não estavam de todo delimitadas, Os sertões, obra maior de Euclides da Cunha, é um livro na encruzilhada entre a literatura, o conhecimento científico e a historiografia, como afirmam vários críticos, desde a pioneira resenha de José Veríssimo, escrita no momento da publicação da obra, em 1902. ${ }^{2}$ O viés propriamente literário da obra, sem dúvida, foi aquele que mais atenção recebeu da crítica, correspondendo à quase totalidade dos estudos publicados, voltados à abordagem de seus aspectos estéticos e formais. Recentemente, o aspecto científico foi contemplado com o estudo de José Carlos Barreto de Santana. ${ }^{3}$ Nele, o autor retraça as relações de Euclides com a nascente comunidade científica brasileira e a aplicação dos conhecimentos geológicos na escrita de Os sertões, enfatizando exatamente a análise da parte tradicionalmente mais desprezada do livro: a primeira, dedicada à terra.

Seguindo perspectiva semelhante à daquele autor, neste texto pretendo estudar, de maneira necessariamente introdutória, o aspecto historiográfico presente na obra de Euclides da Cunha. Em vez de procurar o que há de poético no discurso histórico, aqui pretendo encontrar o que há de historiográfico naquele que foi tomado como um dos textos clássicos de nossa literatura. Mas não pretendo abordar a questão pelo prisma, já clássico, da contribuição de Os sertões na definição de uma memória sobre Canudos, que teria, posteriormente, marcado as interpretações historiográficas sobre o evento. ${ }^{4}$ Aqui, busco me concentrar na relação de Euclides com o processo de construção de uma história paulista, entendida como carro-chefe de um discurso laudatório sobre a identidade regional, iniciada ainda nos tempos do Segundo Reinado e que toma

\footnotetext{
${ }^{2}$ Uma análise da fortuna crítica de Os sertões, principalmente pela historiografia literária, está em BARBOSA FILHO, Hildebrando. Os sertões: Historiografia e esteticidade In: FERNANDES, Rinaldo de (org.). O clarim e a oração, cem anos de Os sertões. São Paulo: Geração Editorial, 2002, p. 315-330. Para uma interessante discussão sobre as diferentes posições da crítica quanto à natureza literária ou historiográfica de Os sertões, ver LEONEL, M. C. \& SEGATO, J. A. Euclides e Rosa, entre sociologia e literatura. Disponível em http://www.acessa.com/gramsci/?page=visua lizar\&id=778. Acesso em: 03/2008. Para uma interpretação diferente da aqui apresentada, e que vê Os sertões como obra essencialmente científica, com verniz literário, ver LIMA, Luiz Costa. Terra ignota: a construção de Os sertões. Rio de Janeiro: Civilização Brasileira, 1997.

${ }^{3}$ Ver SANTANA, José Carlos Barreto. Ciência \& arte: Euclides da Cunha e as ciências naturais. São Paulo: Hucitec; Feira de Santana: Universidade Estadual de Feira de Santana, 2001.

${ }^{4}$ LEVINE, Robert. O sertão prometido. O massacre de Canudos. São Paulo: Edusp, 1995. principalmente o capítulo “Canudos e a visão do litoral: um panorama geral”.
} 
força com a República. Tendo sido realizada por intelectuais da elite de São Paulo, ou a ela relacionados, essa verdadeira tradição historiográfica paulista encontrou, no tratamento da figura do bandeirante, o principal objeto de suas pesquisas historiográficas. Concentro-me, portanto, no estudo do sentido que Euclides da Cunha conferiu à temática do bandeirante em Os sertões. Teria o autor, ao dar tanto destaque ao bandeirante em seus escritos, contribuído para a afirmação do discurso de uma superioridade paulista? ${ }^{5}$ A questão ganha ainda mais relevância se lembrarmos a proximidade de Euclides da Cunha com o grupo do jornal O Estado de S. Paulo e sua participação no Instituto Histórico e Geográfico de São Paulo (IHGSP), duas instâncias de criação e difusão desse paulistanismo ufanista.

Considerando, conforme De Certeau, que "não existe relato histórico no qual não esteja explicitada a relação com um corpo social e com uma instituição de saber”, ${ }^{6}$ abordarei, primeiramente, a criação do Instituto Histórico e Geográfico de São Paulo (IHGSP), instituição social que acolheu a produção dessa historiografia regional paulista, e como Euclides da Cunha nele se inseriu. Posteriormente, abordarei a forma como o autor representa a figura do bandeirante em textos referentes à campanha de Canudos, com destaque para a segunda parte de Os sertões, dedicada ao homem. Sem desconsiderar a importância da inserção de nossos intelectuais em um quadro internacional de circulação de saberes, procuro privilegiar o diálogo e as relações de Euclides com os intelectuais brasileiros, mais especificamente o grupo de historiadores paulistas e em especial com Teodoro Sampaio.

\section{O projeto historiográfico do IHGSP e a inserção de Euclides da Cunha}

Fruto de um amplo investimento do recente governo republicano na criação de instituições de ensino e pesquisa, ${ }^{7}$ o Instituto Histórico e Geográfico de São Paulo (IHGSP), fundado em 1894, representava o coroamento de um esforço iniciado na década de 1870 por alguns intelectuais paulistas. Em sua maior

\footnotetext{
${ }^{5}$ A questão foi levantada em SEVCENKO, Nicolau. Literatura como missão. São Paulo: Companhia das Letras, 2006, p. 148, 168.

${ }^{6}$ DE CERTEAU, Michel. A escrita da história. Tradução de Maria de Lourdes Menezes. Rio de Janeiro: Forense, 2000, p. 94.

${ }^{7}$ Sobre a política cultural dos primeiros governos republicanos em São Paulo, ver ALVES, Ana Maria de Alencar. O Ipiranga reapropriado: ciência, política e poder. O Museu Paulista: 18931932. São Paulo: Humanitas/ FFLCH-USP, 2001.
} 
parte republicanos, suas intenções visavam a reelaborar um discurso identitário regional, dotando-o de um sentido mais próximo às suas aspirações.

A busca de afirmar a existência de uma "exceção paulista", um espírito próprio, diferente e à frente dos demais brasileiros, surgia da recente autoconfiança da elite de novos-ricos do café e visava, dentre outras coisas, a legitimar a reivindicação de autonomia política por parte dos republicanos de São Paulo. Nesse sentido, o estatismo centralizador que identificavam no poder imperial deveria ser abolido por representar um empecilho à livre expansão do "espírito paulista”, entendido como marcado por uma maior independência perante o governo, um maior espírito de iniciativa, um maior dinamismo e adequação ao mundo moderno.

No contexto da propaganda republicana, os intelectuais vinculados à nova proposta política federalista passaram a redimensionar o passado regional paulista, baseando-se em uma ideia fragmentária da nação. O Brasil era visto como um corpo cindido por ambientes e populações diferenciados e mal unidos, o que levava também ao questionamento da existência de uma história brasileira unívoca, possibilitando, assim, a afirmação de uma história paulista original e própria.

Para legitimar a especificidade do passado paulista, autores como o republicano separatista Alberto Salles, ${ }^{8}$ em 1887, apropriavam-se da obra de Oliveira Martins, então renomado historiador português, um dos expoentes da geração portuguesa de 1870. Para esse autor, entre os séculos XVII e XVIII, “apresentamse-nos, na América portuguesa, como duas grandes províncias, cuja história é diversa, porque os seus caracteres naturais e adquiridos foram diferentes até a unificação selada pela independência". ${ }^{9}$ Para Oliveira Martins, no seu livro $O$ Brasil e as colônias portuguesas, de 1880, haveria duas histórias diferentes: a do Norte, centrada nos canaviais de Pernambuco, opulenta, litorânea, dependente do escravo africano e atrelada à metrópole; e a do Sul, centrada em São Paulo, livre e semi-independente, ocupando o interior do continente e desenvolvendo, a seu ver, os germes da nação futura. Assim, na visão de Oliveira Martins, os colonos do Sul, com destaque para os paulistas, foram os principais artífices da futura nação.

\footnotetext{
${ }^{8}$ SALLES, Alberto. A pátria paulista. Brasília: Ed. UNB, 1981.

${ }^{9}$ OLIVEIRA MARTINS. O Brasil e as colônias portuguesas. Lisboa: Guimarães e Cia. Editores, 1978 , p. 75.
} 
Essa visão serviu de referência para uma longa linhagem de autores paulistas, até meados do século XX, servindo de epígrafe para trabalhos de Washington Luis, Paulo Prado, Alfredo Ellis Jr. e Afonso de Taunay. Ela também reforçou a tendência dos republicanos paulistas de investirem na elaboração de uma visão negativa do nortista, apresentado como indolente, aferrado a hábitos do passado e dependente do Estado. Nos artigos separatistas de Martim Francisco de Andrada III ou em escritos políticos do romancista republicano Júlio Ribeiro, de finais da década de 1880, o nortista era personagem onipresente, assumindo o papel de "outro" do paulista, o seu contraponto negativo. ${ }^{10}$

Ao mesmo tempo, a interpretação de Oliveira Martins de uma história específica do Sul, centrada em São Paulo, serviu para que a elite republicana revalorizasse a figura do antigo colono paulista que, somente então, em finais do século XIX, passaria a ser generalizadamente denominado de bandeirante, moldando-o com os principais atributos dessa nova identidade regional. Tratase, de fato, de uma revalorização, pois, desde o seu aparecimento nas letras, no século XVIII até finais do século XIX, a figura do colono paulista (futuro bandeirante) passou por um longo processo de ressignificação. Primeiramente, ela foi louvada, com todos os predicados positivos, pelos cronistas coloniais paulistas de fins do século XVIII: Pedro Taques de Almeida Paes Leme e frei Gaspar da Madre de Deus. ${ }^{11}$ Contudo, desde os anos 1840, ela vinha passando por um sistemático processo de desqualificação por parte da historiografia indianista que, sob patrocínio monárquico no Instituto Histórico Geográfico Brasileiro (IHGB), procurava construir a primeira interpretação oficial de nossa história nacional. ${ }^{12}$ Preocupados em criar uma identidade nacional calcada na valorização do elemento indígena, autores indianistas como Januário da Cunha Barbosa, Gonçalves de Magalhães, Gonçalves Dias e Machado de Oliveira, ainda que valorizassem a atuação dos colonos paulistas como construtores

\footnotetext{
${ }^{10}$ Ver representações negativas do nortista, no contexto da propaganda pelo separatismo paulista em 1887, em ADUCI, Cássia C. A pátria paulista. São Paulo: Arquivo do Estado/ Imprensa Oficial, 2000. RIBEIRO, Júlio. Procelárias. São Paulo: ed. Cultura Brasileira, s/d.

${ }^{11}$ Ver ABUD, Kátia. O sangue intimorato e as nobilíssimas tradições. Tese de doutorado, FFLCH, Universidade de São Paulo, 1985.

${ }^{12}$ Todo o processo de construção de uma identidade paulista por meio da historiografia, abordado neste tópico, e mais especificamente a desqualificação do colono paulista pela historiografia indianista, foram pormenorizadamente estudadas em minha tese de doutorado. Ver FERRETTI, Danilo J. Zioni. A construção da paulistanidade: Historiadores, identidade e política em São Paulo (1856-1930). Tese de doutorado, História Social, FFLCH, Universidade de São Paulo, 2004 (ver principalmente capítulos 2 e 3).
} 
das fronteiras nacionais, tendiam cada vez mais a identificá-los como uma espécie de anti-heróis de nossa história, uma vez que, movidos pela ganância e crueldade, eram responsabilizados pelo extermínio dos indígenas, esteio da nação brasileira, conforme essa interpretação monárquica de nossa identidade. Em contraste com a ação dos bandeirantes paulistas - síntese dos vícios do colonizador -, a visão monárquico-indianista valorizava a figura do jesuíta, entendido como defensor da liberdade dos índios e como o agente civilizador, porque cristão, de nossa história.

Contra essa visão, iniciou-se, na década de 1870, um processo de revalorização da figura do bandeirante, mediante duas vias: a primeira representada pela produção historiográfica do então jovem Capistrano de Abreu e a segunda levada adiante por intelectuais paulistas, na maioria republicanos.

Por seu lado, Capistrano estava interessado em elaborar uma nova síntese de nossa história, calcada nos princípios teóricos do cientificismo positivista e do determinismo geográfico, o que o levou a colocar no centro de seu projeto historiográfico novas temáticas voltadas a esclarecer a forma como se dera a interação entre o colonizador e o meio físico. Assim, em seus artigos da Gazeta de Notícias dos anos 1880, Capistrano esboçava o programa de uma história territorialista, que entendia o processo de formação da nacionalidade como sendo marcado pela "luta territorial”, o embate entre o homem e o meio, o que o levava a privilegiar o estudo da ocupação do interior do território e da abertura de caminhos coloniais, e acabava conferindo uma nova centralidade positiva ao fenômeno das Bandeiras. ${ }^{13}$ De certa forma, com o empenho em elaborar uma história territorialista, Capistrano transpunha para o terreno historiográfico a preocupação de amplos setores de elite que identificavam, na crescente expansão da fronteira agrícola e consequente ocupação territorial por agressiva política ferroviária, os meios mais adequados à construção da modernidade brasileira.

Já a intelectualidade paulista, conforme já mencionado, estava empenhada na construção de uma autoimagem positiva, advindo daí o interesse em revalorizar o antepassado histórico mais evidente. De 1872 a 1876, autores como

\footnotetext{
${ }^{13}$ A referência à "luta territorial” está em ABREU, Capistrano. Variedades. Gravetos de história pátria, Gazeta de Notícias, 9/12/1881. In: Idem. Ensaios e estudos, $4^{a}$ série. Rio de Janeiro: Ed. Civilização Brasileira, 1976, p. 310. Sobre o projeto historiográfico de Capistrano de Abreu, ver RODRIGUES, José Honório. Capistrano de Abreu e a historiografia brasileira. In: Idem (org.). Correspondência de Capistrano de Abreu. Rio de Janeiro: Instituto Nacional do Livro, 1954 e ODÁLIA, Nilo. As formas do mesmo. São Paulo: Ed. da Unesp, 1997.
} 
Azevedo Marques, os republicanos Américo Brasiliense e Martim Francisco Ribeiro de Andrada III ou mesmo o romancista Júlio Ribeiro (como atesta seu romance Padre Belchior de Pontes, de 1876), basearam-se em um imaginário antijesuítico para inverter os termos da interpretação monárquico-indianista. ${ }^{14}$ Assim, para essa verdadeira contra-história republicana, que se formava pela crítica aberta ao indianismo, os vilões passavam a ser os jesuítas - identificados com o controle teocrático de corpos e consciências - e os heróis passavam a ser os colonos paulistas, já chamados de "bandeirantes" e identificados como detentores dos valores mais caros à elite cafeicultora e republicana paulista: espírito livre, “democrático”, independente, conquistador, empreendedor e enérgico. $\mathrm{O}$ bandeirante revalorizado emergia, assim, em finais do século XIX, ao mesmo tempo como carro-chefe de uma historiografia nacional renovada pela temática territorialista, e como um símbolo identitário regional vincado por um forte sentido republicano, fruto do investimento de intelectuais paulistas contra a interpretação monárquica de nosso passado.

Uma vez proclamada a República, a criação do IHGSP assumiu o projeto de institucionalizar a elaboração do discurso identitário regional e a nova visão do bandeirante. ${ }^{15}$ Logo se definem três vertentes internas no instituto, evidenciando sua diversidade política e intelectual: uma minoritária católicomonarquista (Eduardo Prado, Estevão Bourroul, João Mendes de Almeida), uma liberal-republicana (Antônio de Toledo Piza e Washington Luís Pereira de Sousa) e uma territorialista, à qual me restringirei. Essa vertente era formada por autores como o cearense Domingos Jaguaribe, há muito radicado em São Paulo, e os recém-chegados Orville Derby, naturalista norte-americano e o engenheiro baiano Teodoro Sampaio. Todos estavam envolvidos diretamente com a Comissão Geográfica e Geológica de São Paulo, órgão criado em 1886 para viabilizar a política territorialista de ocupação agrícola do oeste paulista, mediante o reconhecimento geológico das áreas destinadas ao avanço da

\footnotetext{
${ }^{14}$ BRASILIENSE, Américo. Lições de história pátria. São Paulo: Typographia da Província, 1875; ANDRADA (III), Martim Francisco Ribeiro de. Precursores da Independência. São Paulo: Typographia Alemã, 1874. Já escrita desde 1872, temos a obra AZEVEDO MARQUES, Manoel Eufrásio de. Apontamentos históricos, geográficos, biográficos, estatísticos, noticiosos da província de São Paulo. São Paulo: Comissão do IV centenário, 1954.

${ }^{15}$ Sobre o IHGSP, ver FERREIRA, Antonio Celso. A epopeia paulista: imaginação literária e invenção histórica. Tese de livre docência. Assis: Unesp, 1988, cap. II; e FERRETTI, Danilo, op. cit., 2004, cap. 6.
} 
frente cafeeira. ${ }^{16}$ Em termos historiográficos, também o caráter territorialista se impunha sobre o grupo que pode ser considerado o representante, no interior do IHGSP, do projeto de uma história nacional entendida como processo de paulatina ocupação territorial, traçado por Capistrano de Abreu, autor que mantinha estreitas relações pessoais com todos os três historiadores, conforme se depreende de sua correspondência.

Dos três, sem dúvida, Teodoro Sampaio foi o que mais se dedicou a escrever sobre o passado paulista. Natural da Bahia, negro e monarquista, Teodoro Sampaio teria tudo para não ser aceito pela fechada elite paulista, não fossem o seu inegável mérito como engenheiro, seu empenho na questão territorial e a proximidade com Antônio Prado, também monarquista e líder da mais poderosa família de São Paulo. Talvez para estreitar os laços com a elite regional e facilitar sua aceitação, Teodoro Sampaio acabou se destacando como um dos principais elaboradores do discurso de valorização do bandeirante, tornando-se um verdadeiro ideólogo da paulistanidade.

Baseando sua análise do passado em teorias do determinismo geográfico, Teodoro Sampaio, na esteira de Capistrano de Abreu, considerava que o problema maior da história brasileira havia sido a dificuldade de ocupar o interior do continente, o que exigia a aclimatação prévia do colono europeu ao meio tórrido americano. Em uma série de artigos publicados na revista do IHGSP, entre 1895 e 1900, na época em que Euclides da Cunha escrevia Os sertões, Teodoro procurava mostrar como, na São Paulo colonial, havia-se encontrado a solução para essa cruciante questão da ocupação do território tropical pelo colonizador europeu, a principal da história brasileira, a seu ver, mediante dois pontos: a) a criação, sob a égide das missões jesuíticas, de um tipo racial novo, o tipo bandeirante, fruto da miscigenação de índio e branco, adaptado ao meio e dotado de espírito de ação, independência e energia inigualáveis; b) a existência, nas capitanias do Sul, de um meio natural propício à entrada para o interior do continente, devido ao seu relevo levemente ondulado, clima ameno e regime fluvial, com rios, como o Tietê, que corriam do leste para o oeste, servindo de vias de penetração. ${ }^{17}$

\footnotetext{
${ }^{16}$ Sobre a Comissão Geográfico e Geológica de São Paulo, ver FIGUEROA, Silvia. Modernos bandeirantes: a CGGSP e a exploração científica do território paulista (1886-1931). Dissertação de mestrado, História, FFLCH, Universidade de São Paulo, 1987.

${ }^{17}$ SAMPAIO, Teodoro. A posse do Brasil meridional. Revista do Instituto Histórico e Geográfico de São Paulo (RIHGSP). São Paulo, vol. 1, 1895; Idem. A fundação da cidade de São Paulo.
} 
Assim, Teodoro Sampaio elaborava uma historiografia que ressaltava a originalidade de São Paulo e identificava, pioneiramente, o bandeirante como fruto de uma mestiçagem positiva, ${ }^{18}$ o que ia na contramão do racismo científico da época e da autovisão de parte da elite regional que, conforme Alberto Salles, afirmava o caráter predominantemente branco da população paulista. ${ }^{19}$ Teodoro também reforçava a imagem do paulista como o herói povoador por excelência, como o agente principal de formação da nação, exatamente pelo caráter mestiço que o habilitava a dominar o território e conquistar o sertão bravio à civilização. Em 1899, afirmava que "o paulista (...) tinha de ser o bandeirante por excelência. A conquista dos sertões estava no seu destino histórico”. ${ }^{20}$ Essa afirmação histórica pouco tinha de neutra, implicando desdobramentos no presente dos historiadores. Pois, na visão de Sampaio, amplamente compartilhada pela elite regional, o verdadeiro herdeiro do antigo bandeirante, construtor da nacionalidade brasileira, era o paulista moderno, mais especificamente o cafeicultor que com seu espírito de iniciativa povoava os sertões do oeste paulista gerando a maior fonte de riqueza e progresso do país. Com a louvação do bandeirante como herói povoador, Sampaio legitimava, simbolicamente, a proeminência econômica e social da cafeicultura paulista.

Da mesma forma que Teodoro Sampaio e outros membros do IHGSP, também Euclides da Cunha não era paulista. Natural de uma família de proprietários remediados da cidade fluminense de Cantagalo, Euclides formou-se nos meios militares da corte. Entrou, em 1886, na Escola Militar da Praia Vermelha, no Rio de Janeiro, onde, a par do interesse pelas teorias cientificistas, militou tenazmente no movimento republicano, o que possibilitou estabelecer o contato com Júlio de Mesquita, dono do jornal A Província (futuro O Estado de S. Paulo), órgão principal do republicanismo paulista e para o qual passou

RIHGS), vol. III, 1897; Idem. São Paulo de Piratininga no fim do sécúlo XVI. RIHGSP, vol. V, 1899-1900; Idem. O sertão antes da conquista. RIHGSP, vol. IV, 1898/1899.

${ }^{18}$ Com isso, Teodoro consolidava uma visão mestiça (fusão de brancos e índios) da identidade paulista que seria incorporada pelos ideólogos regionais do século XX: Paulo Prado, Afonso de Taunay, Alcântara Machado e principalmente Alfredo Ellis Jr. que, baseado no neolamarquismo, se dedicaria a comprovar o caráter eugênico do tipo bandeirante. No mais, o pioneirismo de Teodoro foi relativo, restringindo-se à moderna elaboração do discurso regional, pois, conforme afirma Kátia Abud, desde o século XVIII o cronista frei Gaspar já buscava valorizar a presença do elemento indígena na raiz dos grandes troncos familiares paulistas.

${ }^{19}$ SALLES, Alberto. Pátria paulista. Brasília: ed. UNB, 1981.

${ }^{20}$ SAMPAIO, Teodoro. O sertão antes da conquista. Revista do Instituto Histórico e Geográfico de São Paulo (RIHGSP), vol. IV, 1898/1899. 
a escrever inflamados artigos de propaganda republicana a partir de 1888. Sua mudança para a capital paulista ocorreu em 1895, motivado não somente pelas boas relações com o grupo de $O$ Estado de S. Paulo (OESP), mas também pelas oportunidades que São Paulo, em pleno surto cafeeiro, oferecia a um engenheiro recém-formado. De 1895 a 1904, Euclides viveu em São Paulo, trabalhando como engenheiro civil da Superintendência de Obras do Estado, construindo a infraestrutura necessária à ocupação do interior paulista e compartilhando um ethos característico do grupo territorialista, marcado pelo empenho na construção da nacionalidade pela ocupação efetiva de seu interior despovoado, como fica patente em diversos artigos que publicou. ${ }^{21}$ Assim, em 1902, conclamava:

(...) a nossa engenharia não tem destino mais nobre e mais útil do que a conquista racional de nossa terra.

Cumpre preenchê-lo, reatando de algum modo o primitivo rumo de nossa diretriz histórica, tão bem definida no passado, a despeito do tumultuar revolto das Bandeiras.

Diminuamos o apego exclusivista ao litoral. (...)

Olhemos para os sertões. ${ }^{22}$

O republicanismo e o ethos territorialista, apreendido pela engenharia, foram, dessa forma, alguns elementos que aproximaram Euclides da elite paulista, também ela marcada por esse afã de ocupar o território tão bem representado na figura do bandeirante, conforme explicitado no trecho acima. Quanto a esse ponto, vale lembrar as diversas passagens em que Euclides se autoidentificava como uma espécie de bandeirante moderno. Em 1904, por exemplo, ainda em São Paulo, quando articulava, com José Veríssimo, sua inserção em alguma comissão para reconhecimento da fronteira amazônica, revelava que nutria “esperanças na realização de meu ideal bandeirante. Estou cada vez mais animado em levá-lo por diante. Que melhor serviço poderei prestar à nossa terra? Além disso, não desejo Europa, o boulevard, os brilhos de uma posição, desejo

\footnotetext{
${ }^{21}$ No livro Contrastes e confrontos, Euclides enfeixou diversos artigos, escritos na primeira década do século XX, em que estabeleceu os traços gerais de uma política de conquista e ocupação do sertão. Dentre eles, podemos citar: "Plano de uma cruzada I, II, III”, “Entre o Madeira e o Javari”, “Fazedores de deserto”, “Ao longo de uma estrada”.

${ }^{22}$ CUNHA, Euclides. Olhemos para os sertões. Jornal O Estado de S. Paulo. São Paulo, 18 e 19/março/1902. In: CUNHA, Euclides. Obra completa, vol. 1. Rio de Janeiro: Cia. José Aguiar Editor, 1966, p. 504.
} 
o sertão, a picada, e a vida afanosa e triste de pioneiro” ${ }^{23}$ Fosse na Amazônia ou no sertão do oeste paulista, Euclides nunca deixou de se identificar com o ethos territorialista que projetava na figura do bandeirante.

Além do apoio de Júlio de Mesquita, decisivo para sua inserção na sociedade paulista, desde cedo Euclides da Cunha procurou se inserir na nascente comunidade científica que se formava na capital do estado. Para isso, contou com a amizade de Teodoro Sampaio, que conheceu em 1895, e que passou a frequentar constantemente. Pela sua correspondência publicada, pode-se retraçar a teia de sociabilidade na qual se inseriu. Assim, conheceu também Orville Derby, Domingos Jaguaribe e Alberto Loefgreen, ou seja, exatamente o grupo que compunha a vertente territorialista do IHGSP. ${ }^{24}$

Por indicação desse grupo, apesar de não ter nunca publicado qualquer obra de natureza historiográfica, em 1897, foi aceito no interior do IHGSP, a instituição dedicada a produzir o discurso da paulistanidade. Euclides chegou a compor, em 1898, a Comissão de História de São Paulo, mas não publicou nenhum escrito de sua lavra nas páginas da revista do Instituto. Somente notamos aí, em 1898, uma rápida menção à leitura para seus consócios de um trecho de Os sertões, ainda inédito. E note-se que o trecho lido estava mais voltado ao aspecto climatológico dos sertões do Norte. Isso não significa, porém, que tenha ficado alheio à temática do passado paulista e à historiografia sobre o tema produzida pelo IHGSP. O interesse pelo tema das Bandeiras era, na realidade, anterior à sua entrada no Instituto. Em 1895, ano em que se mudou para São Paulo, manifestou interesse que seu amigo Reinaldo Porchat, pertencente ao grupo do jornal OESP, lhe enviasse "qualquer folheto, qualquer velho alfarrábio que trate da época colonial, de 1640 a 1715; qualquer coisa sobre a antiga São Vicente, princípios de São Paulo, excursões dos bandeirantes etc.”. ${ }^{25}$

Já a interpretação historiográfica do IHGSP, Euclides parece tê-la incorporado por intermédio do contato que passou a ter com Teodoro Sampaio em função do conhecimento que este havia acumulado sobre a geologia e costu-

\footnotetext{
${ }^{23}$ GALVÃO, Walnice N. \& GALOTTI, Oswaldo (orgs.). Correspondência de Euclides da Cunha. São Paulo: Edusp, 1997, p. 211. Ou ainda, escrevendo das margens do Amazonas em 20/05/1905: "creio tanto no meu destino bandeirante que levo esta carta de prego pra o desconhecido com o coração ligeiro". Idem, ibidem, p. 278.

${ }^{24}$ Ver SANTANA, José Carlos Barreto, op. cit., capítulo 1.

${ }^{25}$ Carta a Reinaldo Porchat, 15 de maio de 1895. In: GALVÃO \& GALOTTI (orgs.), op. cit., p. 76.
} 
mes dos sertões baianos. ${ }^{26}$ Antes da partida para Canudos, Teodoro orientou Euclides sobre a realidade que encontraria nos sertões baianos, chegando mesmo a confiar-lhe, sob sigilo, um mapa ainda inédito da região, pivô de um pequeno contratempo político. ${ }^{27} \mathrm{Na}$ realidade, a própria campanha de Canudos e, posteriormente, a transferência de Euclides para São José do Rio Pardo, não impossibilitaram de todo o contato com Teodoro Sampaio e Orville Derby que, em algumas ocasiões, chegaram a visitar o escritor em seu quase exílio às margens do rio Pardo, sugerindo leituras e discutindo o livro em elaboração. ${ }^{28} \mathrm{Em}$ texto de 1919, Teodoro Sampaio relembra a sua interlocução com Euclides no momento em que este elaborava os manuscritos do que viria a ser Os sertões. Discutiam não somente questões referentes ao clima e à composição geológica dos sertões baianos, mas também as características de sua população e aspectos de sua história, conforme o depoimento posterior de Teodoro Sampaio:

Passávamos em revistas essas terras adustas do Nordeste brasileiro que o homem ainda não subjugou e em que a natureza de contínuo vitima o homem, selecionando-o pela energia e resistência que ele opõe às crises periódicas da seca e da fome (...).

Depois falávamos da história deste nordeste indomado onde o brasileiro é sempre o mesmo homem, do Piauí pelo Ceará às terras baianas; o mesmo tipo, os mesmos costumes, o mesmo vestir, o mesmo falar, porque a natureza é a mesma no Parnaíba como no Jaguaribe, no Potengi como no São Francisco. E ele me pedia apontamentos históricos que eu assim, como os possuía, enfeixados em cadernos de notas, de bom grado lhes fornecia (...). ${ }^{29}$

\footnotetext{
${ }^{26}$ Teodoro Sampaio era profundo conhecedor dessa região uma vez que, de 1879 a 1886 , correra o trecho baiano do vale do São Francisco, inicialmente como membro da chamada Comissão Hidráulica, voltada a estudar a navegação interior do país e, depois de 1883, como primeiro engenheiro da Comissão de Melhoramentos da Estrada de Ferro da Bahia ao São Francisco. Para um tratamento mais pormenorizado das relações de Euclides com Teodoro Sampaio ver SANTANA, J. C. B. de, op.cit., p. 90-93.

${ }^{27}$ A não manutenção do sigilo por Euclides motivou uma convocação de Teodoro Sampaio para explicar a situação a Campos Sales que acabou fazendo uma cópia do mapa, logo enviada para o Ministério do Exército. Idem, ibidem, p. 93.

${ }^{28}$ Em carta de 23 de março de 1899, momento em que finalizava a escrita de Os sertões, Euclides revelou que "quando aqui esteve o dr. Derby, recomendou-me uns artigos que têm aparecido (sem assinatura mas visivelmente de Capistrano de Abreu) nos últimos números do Jornal do Comércio Referem-se a assunto pátrio. In GALVÃO \& GALOTTI (orgs.), op. cit., p. 116.

${ }^{29}$ Grifos meus. SAMPAIO, Teodoro. À memória de Euclides da Cunha no décimo aniversário de sua morte. Revista do Instituto Geográfico e Histórico da Bahia. Salvador, vol. 26, nº 45, 1919, p. 252-253.
} 
Retirado no sertão paulista, em plena faina de construir a infraestrutura ferroviária que, a seu ver, possibilitaria a vitória definitiva do homem brasileiro sobre um meio inóspito, Euclides contou com a determinante interlocução dos colegas de IHGSP na sua busca de dar sentido à experiência que vivenciara nos sertões de Canudos e que mudara sua visão da realidade. Em São José do Rio Pardo, na célebre cabana, ele escreveu Os sertões, obra em que a representação do bandeirante assumiu lugar de destaque.

\section{A representação do bandeirante em 0 s sertóes}

Quando, no ano de 1897, se iniciaram os conflitos entre jagunços e forças republicanas em Canudos, Euclides da Cunha encontrava-se em um processo de franca desilusão com o regime republicano que tanto havia lutado para implantar. ${ }^{30}$ Acreditando que a República acabaria com a prática do favor oficial e implantaria uma ordem meritocrática, desde o primeiro ano do novo regime Euclides havia se decepcionado com a ampla difusão das práticas de favorecimento pessoal, oportunismo e instabilidade política que o regime havia incentivado. Desde 1890, sua correspondência revela uma crescente amargura em relação ao novo regime, sentimento diretamente proporcional ao crescimento de uma nostalgia pela pureza dos valores republicanos da época da propaganda. ${ }^{31}$

Mas, com o início da campanha de Canudos, Euclides se viu como que dotado de uma nova injeção de ânimo. Ele avaliou o conflito positivamente, considerando-o uma oportunidade de regeneração do regime, mediante a retomada, pelo enfrentamento militar, dos mais puros ideais republicanos. Nesse sentido, já na Bahia, escreveu uma série de artigos para OESP em que reforçava o discurso oficial do regime que identificava os jagunços como bárbaros atrasados a serviço da restauração monárquica e contra a modernidade representada pela República, contraposição tão bem representada na identificação de Canudos como “A nossa Vendeia”. 32

\footnotetext{
${ }^{30}$ VENTURA, Roberto. Euclides da Cunha e a República. Estudos Avançados. São Paulo: vol. 10, ${ }^{\circ}{ }^{\circ} 26$, jan/abr 1996.

${ }^{31}$ Em correspondência ao pai, de 14 de junho de 1890, já revela seu descontentamento com a "febre egoística” e o desenfreado "filhotismo" que grassava no novo regime, atingindo figuras até então estimadas como Benjamim Constant, líder dos militares republicanos. GALVÃO \& GALOTTI (org.), op. cit., 1997, p. 29-30.

${ }^{32}$ Ver principalmente artigo enviado da Bahia, no dia 15 de agosto de 1897 , em que identifica em Antônio Conselheiro "vícios orgânicos e hereditários tolerados pela política expectante do Império” e que só então a República, em um movimento tonificante, viria pela primeira vez repelir.
} 
É nesse contexto que encontramos uma das primeiras referências de Euclides às Bandeiras e ao bandeirante. Nela, o discurso laudatório da superioridade paulista se fez presente quando, em artigo para OESP de outubro de 1897, elogiou a atuação exemplar e incomparável do batalhão paulista no teatro de Canudos: fora dos mais disciplinados, competentes e bravos, despertando admiração na população e no comando. E essa atuação exemplar dos paulistas no sertão era relacionada ao seu passado bandeirante:

Mas não era a primeira vez que os paulistas se aventuravam a arrancadas nos sertões.

O episódio trágico dos Palmares e a epopeia ainda não escrita dos bandeirantes foram criados pela índole aventureira e lutadora dos sulistas ousados. E o batalhão de São Paulo, heroico e desassombrado no combate, fez reviver, por um momento, numa página da história do presente, todo o vigor guerreiro e toda a índole varonil dos valentes caídos há dois séculos. ${ }^{33}$

Euclides identificava, assim, as forças republicanas do batalhão de São Paulo como detentoras da heroicidade épica das Bandeiras, reproduzindo o discurso da paulistanidade elaborado pelo IHGSP que identificava no paulista moderno o herdeiro do bandeirante na faina de ocupar e submeter o sertão. O espírito bandeirante, agente maior da formação da nacionalidade, renascia do lado dos vencedores.

Mas a experiência de Canudos, o contato direto com a violência inaudita do exército republicano, levou Euclides a reavaliar seu otimismo, aprofundando ainda mais a aversão que já trazia ao novo regime republicano e aos novos donos do poder. Essa crítica e aversão se manifestariam não somente em Os sertões, “um livro vingador”, conforme o próprio Euclides o considerava, mas também em artigos em que atacava diretamente a forma desertificadora como se dava a ocupação territorial levada adiante pela elite paulista. ${ }^{34}$

CUNHA, Euclides. Canudos e inéditos. São Paulo: Melhoramentos, 1967, p. 45-137.

${ }^{33}$ CUNHA, Euclides. O batalhão de São Paulo. Jornal O Estado de S. Paulo. 26/outubro/1897. In: CUNHA, Euclides, op. cit., p. 137.

${ }^{34}$ Em artigos como “Distribuição dos vegetais no Estado de São Paulo”, “Fazedores de desertos” e "Planos de uma cruzada (II e III)”, os dois últimos publicados em Contraste e confrontos, Euclides desenvolve uma critica ecológica à expansão da monocultura cafeeira paulista que por razões de espaço não cabe aqui desenvolver, mas que acaba por reforçar a identificação negativa do paulista tanto o antigo (bandeirante) quanto o moderno (cafeicultor) - como sendo um “criador de deserto", invertendo, portanto, o sentido do discurso regionalista da elite paulista que se autoproclamava como agente civilizador, por proporcionar a ocupação econômica e populacional do sertão. 
Em Os sertões, Euclides ultrapassou a mera representação da campanha de Canudos e acabou escrevendo uma obra que era um verdadeiro ensaio de interpretação nacional. O episódio foi apresentado como representativo de uma luta entre o esquecido mundo sertanejo dos jagunços e as populações litorâneas, representantes de uma pretensa moderna civilização republicana. Buscando compreender o fenômeno do conselheiro e seus seguidores, o autor voltou-se ao estudo pormenorizado da sociedade e ambiente sertanejos, lançando as bases da matriz de interpretação da nacionalidade que contrapõe o sertão ao litoral, que teria sua consagração no século XX, conforme estudo de Nísia Trindade Lima. ${ }^{35}$ Aqui nos interessa a segunda parte do livro $O$ homem, em que Euclides da Cunha procurou traçar o perfil racial e psicológico dos sertanejos, para isso apresentando uma original representação do passado nacional.

Infelizmente, Euclides pouco citava suas fontes bibliográficas, dificultando nosso trabalho de definir a sua interlocução com a produção historiográfica de sua época. Mas nas poucas citações explícitas, a historiografia paulista se fez presente, não somente por meio do cronista colonial Pedro Taques de Almeida Paes Leme, espécie de pai fundador da tradição regional, mas também por intermédio de autores recentes: João Mendes de Almeida, expoente de uma historiografia paulista católica e monarquista, e os sócios do IHGSP e seus amigos próximos Orville Derby e Teodoro Sampaio. Assim, minha abordagem de Os sertões será marcada por um jogo de aproximação e distanciamento em relação à historiografia produzida no IHGSP.

Um primeiro ponto em comum estava no enfoque geral utilizado na abordagem da história brasileira. Euclides, de forma semelhante a Capistrano de Abreu, Teodoro Sampaio e autores paulistas como o republicano Alberto Salles e o posterior Afonso de Taunay, se identificava com uma interpretação territorialista do passado brasileiro que, na interface entre a história e a geografia, compreendia a formação nacional como marcada pelo embate entre o homem e o meio físico. Lastreada, teoricamente, no determinismo geográfico de autores como o inglês Buckle, ou numa leitura original de Hegel, Euclides propunha que, para compreender o homem brasileiro, se estudasse a geografia e o clima das diversas regiões do país, pois esses seriam os fatores determinantes tanto do processo histórico quanto dos tipos humanos dele advindos. Nesse aspecto

\footnotetext{
${ }^{35}$ LIMA, Nísia Trindade. Um sertão chamado Brasil. Rio de Janeiro: Revan, IUPERJ, Ucam, 1999, p. 67-72.
} 
teórico, ainda que levasse em consideração os princípios do racismo científico, fazia-o de forma heterodoxa e limitada, criticando o apego exagerado e irrefletido a ele devotado por amplos setores da intelectualidade brasileira, descartando mesmo os princípios do branqueamento e as práticas frenológicas, entendidas como abusos de um exagerado materialismo filosófico. ${ }^{36} \mathrm{Em}$ sua análise do processo social e histórico, tal qual seus colegas de IHGSP, Euclides ressaltava a prioridade do elemento geográfico, do meio físico, uma vez que este era responsável pela própria conformação dos tipos raciais. Assim, mais do que a raça, o meio físico se projetava como fator determinante da ação humana.

Outra semelhança estava em que Euclides, da mesma forma que vários autores paulistas, apresentava, em Os sertões, uma visão cindida da nacionalidade. Ou seja, concebia o Brasil como um corpo físico e social marcado pela predominância das diferenças regionais em detrimento de uma ausente unidade orgânica, que Euclides procurava ansiosamente construir (dentre outros meios por arrojada política viária) ${ }^{37}$ para, só assim, completar o processo de formação da nação. Essa visão cindida aparece, inicialmente, quando procura retratar o meio físico que condiciona a formação histórica do tipo racial sertanejo.

A primeira cisão que apresenta é aquela entre costa e sertão, entendidos como duas paisagens geográficas e humanas completamente diferentes. O sertão, como vimos, aparece, inicialmente, como território inóspito, um empecilho à ocupação do colono, principalmente o sertão do Norte, a região semidesértica da caatinga, que repelia o europeu. Esse imigrante, no entanto, encontrou melhores possibilidades de penetração nos sertões do Sul, segundo Euclides, que, assim,

\footnotetext{
${ }^{36}$ Questionando os "nossos antropólogos", Euclides afirma que "Forrando-se, em geral, à tarefa penosa de subordinar as suas pesquisas a condições tão complexas, têm atendido sobremaneira ao preponderar das capacidades étnicas. Ora, a despeito da grave influência destas, e não a negamos, elas foram entre nós levadas ao exagero (...). [Os nossos antropólogos] Começam em grande parte excluindo os materiais objetivos oferecidos pelas circunstâncias mesológicas e históricas.” CUNHA, Euclides. Os sertões. Brasília: Ed. UnB, 1963, p. 59-60. As críticas às teorias de branqueamento que, ao cabo, balizavam sua crítica ao privilégio concedido ao imigrante europeu estão na pág. 60. Já a crítica à frenologia está na pág. 93.

${ }^{37}$ Os projetos de integração futura da nação por meio de uma redentora política viária encontramse definidos nos artigos de cunho territorialista (citados na nota $\mathrm{n}^{\circ} 19$ ) enfeixados em Contrastes e confrontos. Analisando-os, destaca-se, mais uma vez, a semelhança com Capistrano de Abreu que também compreendia a formação da nação por meio da abertura de uma rede de caminhos coloniais, conforme definiu em seu clássico Caminhos antigos e povoamento. Assim, estabeleciase entre ambos um trabalho complementar, pois, de forma espontânea e não combinada, enquanto Capistrano buscou identificar o processo integrador no passado, Euclides projetava os meios de sua conclusão no futuro.
} 
estabelecia a segunda grande cisão que estrutura a representação do processo formador nacional na opinião do escritor: a cisão entre Norte e Sul.

Para Euclides, havia "uma diferença essencial entre o Norte e o Sul, absolutamente distintos pelos regimes meteorológicos, pela disposição da terra e pela transição variável entre o sertão e a costa”. ${ }^{38}$ Essa diversidade radical de meio físico é apresentada como surtindo um reflexo profundo na formação histórica brasileira, também ela cindida entre Norte e Sul, à semelhança da interpretação de Oliveira Martins, autor que parece ter lastreado essas passagens de Euclides, mas que em nenhum momento é citado. Para Euclides, “enfeudado o território, dividido pelos donatários felizes, e iniciando-se o povoamento do país com elementos idênticos (...), abriu-se separação radical entre o Sul e o Norte. Não precisamos rememorar os fatos decisivos das duas regiões. São duas histórias distintas, em que se averbam tendências opostas”. ${ }^{39}$

Assim, o Norte, foco de todos os males, marcado por um calor que deprime e exaure o habitante, provocou uma aclimatação que levou à regressão do europeu, diminuindo seu tônus muscular e tornando-o apático. Na região amazônica, o colono europeu decaiu, vencido pelo meio e dominado pelo selvagem. Nos canaviais de Pernambuco e Bahia - capitanias sujeitas à rotina, "amorfas e imóveis”, conforme as caracterizaram Oliveira Martins e boa parte dos historiadores paulistas - o colono ficou preso ao litoral, sujeito à "centralização estúpida" dos representantes da coroa e ao domínio espiritual da Companhia de Jesus. ${ }^{40}$

Já no Sul, a situação era radicalmente outra, representada sob um inegável sentido positivo. Aí, em função de um clima mais brando, desenvolveu-se outra sociedade, marcada por "maior vigor no povo mais heterogêneo, mais vivaz, mais prático e aventureiro, um largo movimento progressista, em suma” . ${ }^{41}$ Aí foi possível uma aclimatação mais adequada do colono português, que manteve o vigor original que havia impulsionado a epopeia das grandes conquistas ultramarinas.

Da fusão desse colono com os índios surgiu o tipo do bandeirante paulista, apresentado, em tons grandiloquentes, por Euclides como um "tipo autônomo, aventuroso, rebelde, libérrimo, com a feição perfeita de um dominador da terra”, ${ }^{42}$ um "povo estranho de mestiços levantadiços” que “volviam-se em luta

\footnotetext{
${ }^{38}$ Idem, ibidem, p. 65 .

${ }^{39}$ Idem, ibidem, p. 70.

${ }^{40}$ Idem, ibidem, p. 70.

${ }^{41}$ Idem, ibidem, p. 70.

${ }^{42}$ Idem, ibidem, p. 70
} 
aberta com a corte portuguesa, numa reação tenaz contra o jesuíta”. ${ }^{43}$ Ele seria uma síntese entre a energia europeia herdada, incorruptível, dos navegadores portugueses e a capacidade de aclimatação ao tórrido meio americano do indígena, o que o atava à nova terra, possibilitando inclusive a oposição ao colonizador europeu. Também o tema da serra do Mar, tão desenvolvido por autores paulistas do final do século XIX, como Alberto Salles e Teodoro Sampaio (e posteriormente, nos anos 1920, por Paulo Prado), foi apresentado por Euclides como um fator que impulsionava o paulista para o sertão, anulando o "apego irreprimível ao litoral” que marcava os colonos ao Norte. O rio Tietê, por sua vez, facilitaria a comunicação com o interior, articulando a cisão entre litoral e sertão que, no Sul, seria mais branda. Assim, em suas páginas, os bandeirantes paulistas são descritos com a mesma qualidade a eles conferida por Teodoro Sampaio: a de conquistadores do sertão e formadores do território nacional.

Até esse primeiro movimento de caracterização das Bandeiras, Euclides não somente se manteve nos limites do discurso historiográfico veiculado pela intelectualidade paulista, como apresentou uma de suas mais bem elaboradas manifestações. Em sua visão da formação nacional, tudo tendia à dissolução de um corpo mal unido, visão essa que, não por acaso, chegou a justificar o separatismo de um republicano paulista como Alberto Sales. Mas, a partir do momento em que passou a se aproximar da caracterização da formação histórica do tipo racial das populações de Canudos, Euclides tendeu a se distanciar da historiografia paulista, iniciando o processo de inversão simbólica do sentido do mito bandeirante.

Ao tratar da "gênese dos jagunços", Euclides redefinia sua trajetória e, num segundo movimento, se distanciava da historiografia paulista para se aproximar do historiador sergipano João Ribeiro, duas vezes citado, que dava destaque ao papel unificador do rio São Francisco. Estudando a formação racial das populações que se fixaram no vale desse rio, Euclides o descrevia como marcado por três zonas: as altas cabeceiras, dominadas pela agitação mineira identificada como fruto das Bandeiras; o curso inferior, próximo ao mar e dominado pela ação dos jesuítas; e o curso médio, exatamente a região de Canudos, onde avulta o tipo do vaqueiro, antepassado do jagunço. Nesse sentido, para o autor, o rio São Francisco teria uma função fundamental na formação nacional por ser o traço de união entre o Norte e o Sul, atenuando a cisão entre as partes que impedia a integração orgânica do território e sociedade nacionais. O que até então era dissolução pas-

\footnotetext{
${ }^{43}$ Idem, ibidem, p. 83.
} 
sava a tender à integração. Em sua porção média, o São Francisco se apresentava, por suas características mesológicas, como um agente de fixação da população.

Mas, ao definir a natureza dessa população, um terceiro movimento se apresentava e aproximava Euclides, novamente, da historiografia paulista, porém de uma vertente um tanto marginal, principalmente no contexto de afirmação do republicanismo laicizante: a vertente católico-ultramontana de João Mendes de Almeida. Maranhense de nascimento, João Mendes projetou-se como o líder maior da ala mais ortodoxa do partido conservador de São Paulo nas duas últimas décadas da monarquia. ${ }^{44}$ Tradicionalista extremado, foi duramente atacado tanto por republicanos quanto por conservadores da ala oposta que não deixavam de mobilizar o notório preconceito antinortista e o acusavam de ser um estrangeiro em São Paulo. Visando, dentre outras coisas, a construir uma autoimagem que afirmasse sua paulistanidade sem negar a origem maranhense, João Mendes publicou, em 1886, o livro Algumas notas genealógicas, espécie de manifesto intelectual do grupo ultramontano paulista. Calcado no mais radical providencialismo agostiniano, nele trançava as origens de sua família com a história colonial paulista, reforçando exatamente a ideia que seria apropriada por Euclides em Os sertões: a ocupação do sertão nordestino ter-se-ia dado principalmente pelos bandeirantes paulistas, origem remota de várias famílias maranhenses, dentre as quais os Mendes de Almeida que assim integravam-se à mais genuína cepa paulista.

Claro que o ateu Euclides dispensou o providencialismo ultramontano de João Mendes, mas, nesse terceiro movimento, destacou e reformulou a ideia básica da origem bandeirante das populações nortistas. Assim, ao caracterizar a origem da população que formou os criadores de gado da região do médio São Francisco, ou seja, da região de Canudos, Euclides a identificou como composta, em sua grande maioria, por bandeirantes paulistas. Nas origens da população do sertão de Canudos, na gênese dos jagunços, estava o bandeirante. Ao afirmá-lo, Euclides transferia ao jagunço todos os atributos positivos que há décadas os historiadores da paulistanidade atribuíam aos bandeirantes. O principal deles, as qualidades de adequação ao meio físico americano, fruto da consolidação de um tipo étnico mameluco, mistura reiterada de branco com índio em que o negro es-

\footnotetext{
${ }^{44}$ Em 1879, ocorreu um grande racha no interior do partido conservador de São Paulo, com a criação da União Conservadora, uma nova ala modernizadora do partido, atrelada a interesses cafeeiros e liderada por Antonio Prado, então principal figura política provincial. Sobre a cisão ver LEVI, Darell. A família Prado. São Paulo: Cultura 70, 1977.
} 
tava quase ausente. Assim, o jagunço era representado como "uma raça de cruzados idênticos àqueles mamalucos estrênuos que tinham nascido em São Paulo" ${ }^{4}$

Bandeirante sulista ancorado nos sertões do Norte, ponto médio entre os nortistas e os sulistas, entre jesuítas e bandeirantes, entre brancos e índios, o jagunço de Euclides era apresentado como o resultado da fusão equilibrada de todos os elementos díspares que formavam a nação. O sertanejo do médio São Francisco - "colateral provável dos paulistas" - era identificado como um tipo racial fixo, sem a variabilidade que o racismo científico do período identificava nos mestiços. Em uma realidade marcada pela diversidade informe de paisagens naturais, agentes históricos e tipos raciais, que implicava uma indefinição de elementos comuns definidores de um caráter nacional, a figura do jagunçobandeirante aparecia como único elemento estável e definido, verdadeira síntese unificadora da nação nascente. Por isso, fazendo uma releitura em chave geológica da teoria de formação da nacionalidade defendida por Von Martius (e que orientou boa parte da produção historiográfica do séc. XIX brasileiro), ${ }^{46}$ Euclides identificava no jagunço canudense a "rocha viva da nossa raça" ${ }^{47}$ Era a verdadeira síntese biológica sobre a qual deveria ser construído o povo brasileiro, somente faltando a introdução da cultura moderna e dos valores da civilização no espírito desses fortes sertanejos.

Se os jagunços eram o cerne da nação, o eram, dentre outros motivos, por serem os únicos a manterem intactos os atributos raciais ancestrais do tipo paulista. Euclides se apropriava da ideia, presente em autores como Saint Hilaire e Machado de Oliveira, ${ }^{48}$ de que houve uma decadência do paulista no século XVIII que

\footnotetext{
${ }^{45}$ CUNHA, Euclides, op. cit., 1963, p. 72.

${ }^{46}$ Sobre o ensaio de Von Martius e seu impacto na historiografia do século XIX, ver CEZAR, Temístocles. Como devia ser escrita a história do Brasil no séc. XIX. Ensaio de história intelectual. In: PESAVENTO, Sandra J. (org.) et al. História cultural: experiências de pesquisa. Porto Alegre: ed. UFRGS, 2003.

${ }^{47}$ Definição descrita na famosa nota V à terceira edição, a partir de uma bela metáfora geológica, que toma a nação como semelhante ao granito em sua composição tripartite. "De fato, a nossa formação como a do granito surge de três elementos principais”. Da mesma forma como neste parte-se de uma superfície formada da junção dispersa dos três materiais diversos (quartzo, feldspato e mica) para uma base formada pela rocha viva, homogênea e indissolúvel, também a nação seria formada em sua superfície litorânea pela junção informe de diversos tipos raciais (negro, branco e índio) e somente no sertão se atingiria o cerne duro, compacto e definido do sertanejo, síntese formadora do tipo racial brasileiro. Vale lembrar que, para Euclides, da mesma forma que para Von Martius, o negro teria um caráter secundário na formação da síntese nacional, daí a valorização do bandeirante, no qual os elementos branco e índio predominam. Idem, ibidem, p. 354.

${ }^{48}$ SAINT-HILAIRE, Auguste. Quadro histórico da província de São Paulo [1851]. In: Idem.
} 
levou à perda de suas qualidades originais. Assim, no Sul, o bandeirante havia desaparecido, transformando-se no caipira, para Euclides uma espécie de ruína humana, um "decaído", um "desfibrado, sem o desempenho dos titãs bronzeados que lhe formam a linha obscura e heroica (...)”, em tudo diferente “daqueles caboclos rijos e mateiros, que abriram neste vale as picadas atrevidas das bandeiras”. ${ }^{4}$

Mas no Norte a situação foi outra. O bandeirante fixado passou por um processo de isolamento, fruto da ação conjunta do latifúndio e do meio inóspito, que implicou a manutenção e transmissão de seus traços ancestrais ao jagunço. Nesse sentido, Euclides representava o sertanejo do Norte como um “retrógrado”, ou seja, um tipo racial estático, parado no tempo, um bandeirante seiscentista que havia trazido até o presente as suas características raciais básicas, o exato inverso do caipira do Sul que, como vimos, seria um “decaído”.

Com essa caracterização, o tratamento do tema do bandeirante realizado por Euclides não somente rompia com o discurso identitário da elite republicana paulista como invertia o seu sentido. Pois, como lembramos, para o discurso da paulistanidade, o principal agente formador da nação era o bandeirante e os seus dignos herdeiros eram os membros da moderna elite cafeicultora paulista. Euclides mantinha a centralidade do bandeirante mas negava exatamente esse vínculo entre o paulista antigo-bandeirante e o paulista moderno-cafeicultor, colocando o jagunço de Canudos como o principal herdeiro da grandeza bandeirante. Automaticamente, Euclides invertia a valoração entre Norte e Sul: os sertões do Norte, pelas características físicas de inacessibilidade, passavam a ser os detentores do elemento racial positivo, enquanto os sertões do Sul passavam a abrigar uma população decaída e arruinada. Para Euclides, o espírito bandeirante vivia latente nas populações do sertão do Norte, o que significava alçar ao posto de representante maior da nacionalidade exatamente aquele grupo - o nortista - que era identificado pela elite paulista como seu contrário negativo.

Assim, por essa torção simbólica, Euclides se distanciava do discurso laudatório da paulistanidade (o que o diferenciava de Teodoro Sampaio) e manifestava sua crítica mordaz em relação à ação do exército republicano. Ressignificando o símbolo maior dos vencedores - o bandeirante-ele o identificava com os vencidos.

Viagem à Província de São Paulo. São Paulo: Martins ed., 1972. OLIVEIRA, Joaquim José Machado d'. Quadro histórico da Província de São Paulo. [1864] São Paulo: Governo do Estado de São Paulo, 1978.

${ }^{49}$ CUNHA, Euclides da. Entre ruínas. In: Idem. Contrastes e confrontos. Rio de Janeiro: Record, 1975, p. 193. 


\section{Conclusão}

Podemos, agora, voltar à questão inicial: ao conferir destaque à figura do bandeirante, teria Euclides da Cunha participado da difusão do discurso da superioridade paulista? Qual sentido conferiu ao bandeirante?

A postura de Euclides em relação ao bandeirante foi marcada por certa ambiguidade, tendo apresentado diferentes posições em diferentes contextos. Euclides reforçava a visão laudatória não somente quando identificava sua atividade de engenheiro como versão moderna do bandeirante, mas também quando, como correspondente no teatro de guerra, comparava o batalhão paulista aos bandeirantes destruidores de Palmares e conquistadores do sertão. Fazia o mesmo em artigo de 1903, em que apresentava as ferrovias paulistas do café como dignas continuadoras da obra de ocupação territorial iniciada pelos antigos colonos paulistas.

Em Os sertões, porém, realizou a inversão de sentido acima discutida. Apesar de se aproximar do discurso historiográfico do IHGSP, mediante o diálogo com seu amigo Teodoro Sampaio, ao conferir centralidade ao bandeirante na formação nacional, ao adotar um enfoque geral característico da historiografia territorialista, ao apresentar uma visão da nação como cindida entre Norte e Sul e ao identificar, no tipo bandeirante, a "rocha viva da raça", tipo original, fixo, forte, aclimatado e apto a ocupar o sertão, apesar desses pontos em comum com o discurso da paulistanidade, ele rompeu com ele ao negar o seu feixe de ouro: a ideia de que o paulista moderno era o digno herdeiro de todas essas virtudes do bandeirante.

Pois a grande originalidade da representação historiográfica de Euclides estava em apresentar o jagunço de Canudos como o verdadeiro herdeiro da grandeza bandeirante. Ao contrário do discurso vigente, os derrotados pelas tropas da República não eram os inimigos da nação, mas os próprios representantes do seu cerne mais profundo, identificado diretamente com o bandeirante. As tropas republicanas, atacando os jagunços, feriam a alma da nação.

\section{Referências bibliográficas}

ABREU, Capistrano. Ensaios e estudos. $4^{a}$ série. Rio de Janeiro: Ed. Civilização Brasileira, 1976.

ABUD, Kátia. O sangue intimorato e as nobilíssimas tradições. Tese de doutorado, História, FFLCH, Universidade de São Paulo, 1985.

ADUCI, Cássia C. A pátria paulista. São Paulo: Arquivo do Estado/ Imprensa Oficial, 2000.

ALVES, Ana Maria de Alencar. O Ipiranga reapropriado: ciência, política e poder. 
O Museu Paulista: 1893-1932. São Paulo: Humanitas/ FFLCH-USP, 2001. ANDRADA, Martim Francisco Ribeiro de. Precursores da Independência. São Paulo: Typographia Alemã, 1874.

AZEVEDO MARQUES, Manoel Eufrásio de. Apontamentos históricos, geográficos, biográficos, estatísticos, noticiosos da Província de São Paulo. São Paulo: Comissão do IV centenário, 1954.

BARBOSA FILHO, Hildebrando. Os sertões: Historiografia e esteticidade. In: FERNANDES, Rinaldo de (org.). O clarim e a oração, cem anos de Os sertões. São Paulo: Geração editorial, 2002.

BRASILIENSE, Américo. Lições de história pátria. São Paulo: Typographia da Província, 1875

CEZAR, Temístocles. Como devia ser escrita a história do Brasil no século XIX. Ensaio de história intelectual. In: PESAVENTO, Sandra J. (org.) et al. História cultural: experiências de pesquisa. Porto Alegre: ed. UFRGS, 2003.

CUNHA, Euclides da. Contrastes e confrontos. Rio de Janeiro: Record, 1975, p. 193. CUNHA, Euclides da. Os sertões. Brasília: Ed. UnB, 1963

CUNHA, Euclides da. Canudos e inéditos. São Paulo: Melhoramentos, 1967, p 45-137.

CUNHA, Euclides da. Obra completa, vol. 1. Rio de Janeiro: Cia. José Aguiar Editor, 1966.

DE CERTEAU, Michel. A escrita da história. Rio de Janeiro: Forense, 2000.

FERREIRA, Antonio Celso. A epopeia paulista: imaginação literária e invenção histórica. Tese de livre docência. Assis: Unesp, 1988.

FERRETTI, Danilo J. Zioni. A construção da paulistanidade: Historiadores, identidade e política em São Paulo (1856-1930). Tese de doutorado, História Social, FFLCH, Universidade de São Paulo, 2004.

FIGUEROA, Silvia. Modernos bandeirantes: a CGGSP e a exploração científica do território paulista (1886-1931). Dissertação de mestrado, História, FFLCH, Universidade de São Paulo, 1987.

GALVÃO, Walnice N. \& GALOTTI, Oswaldo (orgs.). Correspondência de Euclides da Cunha. São Paulo: Edusp, 1997.

LEONEL, M.C. \& SEGATO, J.A. Euclides e Rosa, entre sociologia e literatura. Disponível em http://www.acessa.com/gramsci/?page=visualizar\&id=778. Acesso em 03/2008.

LEVI, Darell. A família Prado. São Paulo: Cultura 70, 1977.

LEVINE, Robert. O sertão prometido. O massacre de Canudos. São Paulo: Edusp, 1995.

LIMA, Luiz Costa. Terra ignota: a construção de Os sertões. Rio de Janeiro: Ci- 
vilização Brasileira, 1997.

LIMA, Nísia Trindade. Um sertão chamado Brasil. Rio de Janeiro: Revan, IUPERJ, Ucam, 1999.

ODÁLIA, Nilo. As formas do mesmo. São Paulo: Ed. da Unesp, 1997.

OLIVEIRA, Joaquim José Machado d'. Quadro histórico da Província de São Paulo. [1864] São Paulo: Governo do Estado de São Paulo, 1978.

OLIVEIRA MARTINS. O Brasil e as colônias portuguesas. Lisboa: Guimarães e Cia. Editores, 1978.

RIBEIRO, Júlio. Procelárias. São Paulo: ed. Cultura brasileira, s/d.

RODRIGUES, José Honório. Capistrano de Abreu e a historiografia brasileira In: RODRIGUES, José Honório (org.). Correspondência de Capistrano de Abreu. Rio de Janeiro: Instituto Nacional do Livro, 1954.

SAINT-HILAIRE, Auguste. Quadro histórico da Província de São Paulo [1851]. In: SAINT-HILAIRE, Auguste. Viagem à Província de São Paulo. São Paulo: Martins ed., 1972.

SALLES, Alberto. A pátria paulista. Brasília: Ed. UNB, 1981.

SAMPAIO, Teodoro. A posse do Brasil meridional. Revista do Instituto Histórico e Geográfico de São Paulo (RIHGSP), vol. 1, 1895.

SAMPAIO, Teodoro. A fundação da cidade de São Paulo. RIHGSP, vol. III,1897.

SAMPAIO, Teodoro. São Paulo de Piratininga no fim do séc. XVI. RIHGSP, vol. V, 1899-1900.

SAMPAIO, Teodoro. O sertão antes da conquista. RIHGSP, vol. IV, 1898/1899.

SAMPAIO, Teodoro. Àmemória deEuclides da Cunhano décimo aniversário de suamorte. RevistadoInstituto Geográfico e Histórico da Bahia. Salvador, vol.26, n 45, 1919.

SANTANA, José Carlos Barreto. Ciência \& arte: Euclides da Cunha e as ciências naturais. São Paulo: Hucitec; Feira de Santana: Universidade Estadual de Feira de Santana, 2001.

SEVCENKO, Nicolau. Literatura como missão. São Paulo: Cia. das Letras, 2006.

VENTURA, Roberto. Euclides da Cunha e a República. Estudos Avançados. São Paulo: vol. 10, n ${ }^{\circ}$ 26, jan/abr 1996. 